\title{
A rare case of hypoplastic left heart syndrome in pregnancy and its outcome
}

\author{
Akshatha DS, Shakuntala PN, Sreelatha S, Sumayya, Shruthi \\ Corresponding author: Dr. Sreelatha S, Professor, Department of Obstetrics and Gynaecology, \\ ESIMC PGIMSR, Rajaji nagar, Bangalore, Karnataka, India; \\ Email : drachalasahai_2@rediffmail.com
}

Distributed under Attribution-Non Commercial - Share Alike 4.0 International (CC BY-NC-SA 4.0)

\section{$\underline{\text { ABSTRACT }}$}

\begin{abstract}
Hypoplastic left heart syndrome is abnormal development of left sided cardiac structure, leading to obstruction to blood flow from the left ventricular outflow tract. We are presenting a case of primigravida with 35 weeks period of gestation with gestational hypertension with left hypoplastic heart syndrome with single umbilical artery which was diagnosed at 24 weeks anomaly scan but she continued the pregnancy. Emergency caesarean section was done and a live male baby was delivered but shifted to NICU in view of antenatally diagnosed hypoplastic left heart syndrome. Baby was discharged on day 8 of life, on day 21 of life baby presented with gasping breaths. Chest x-ray showed extensive infiltrates and baby died due to pneumonia and cardiac arrest.
\end{abstract}

Keywords: Congenital heart disease, hypoplastic left heart syndrome, LSCS, preeclampsia, cardiologists.

Hypoplastic left heart syndrome (HLHS) is an etiologically multifactorial congenital heart disease affecting in 1 in 5000 newborns. This syndrome has been reported to occur in approximately $0.016 \%$ to $0.036 \%$ of all live births ${ }^{1,2}$. This syndrome was first described by Lev in $1952^{3}$, later it was named by Noonan and Nadas in $1958^{4}$. This syndrome represents in $2-9 \%$ of congenital heart disease $^{5}$. It is characterized by underdevelopment or absence of the left ventricle. Features of HLHS include varying degrees of hypoplasia of left ventricle, mitral valve and aortic valve atresia or stenosis, and hypoplasia of the ascending aorta. According to Barber $\mathrm{G}$ et al coarctation of the aorta may be associated in $67 \%$ to $80 \%$ of cases ${ }^{6}$. It occurs predominantly in males ${ }^{7}$. It also has genetic predisposition. Etiology is idiopathic. This syndrome can be diagnosed by anomaly scan and confirmed by fetal echocardiography.

Case

We are presenting a case of primigravida with 35 weeks of gestation with left hypoplastic heart syndrome (figure 1) with single umbilical artery (diagnosed at 24 weeks of gestation on ultrasonography anomaly scan). She was coming for regular antenatal checkups, prenatal counseling (cardiology and paediatric counseling) was done to the parents regarding need for surgery, mortality and morbidity after birth. Patient came with complain of headache and vomiting since 1 day.

On examination no pallor, no pedal edema, pulse rate $82 / \mathrm{min}$, blood pressure was $160 / 100 \mathrm{~mm}$ of $\mathrm{Hg}$; per abdominal examination - epigastric tenderness present, uterus 36 weeks, irritable, cephalic presentation, fetal heart rate good. Per vaginal examination observed partially effaced cervix, os $2 \mathrm{~cm}$ dilated, bag of membranes forming, vertex - 2 station and pelvis adequate. She was started on antihypertensives in view of impending eclampsia. Emergency LSCS was done and a live male baby was delivered who cried immediately after birth (Apgar score in 1minute $-7 / 10,5$ minute $-8 / 10$ ) but was shifted to NICU in view of antenatally diagnosed hypoplastic left heart syndrome. The condition of mother was good and suture

Received: $15^{\text {th }}$ September 2020, Peer review completed: $4^{\text {th }}$ February 2021, Accepted: $30^{\text {th }}$ March 2021.

Akshatha DS, Shakuntala PN, Sreelatha S, Sumayya, Shruthi. A rare case of hypoplastic left heart syndrome in pregnancy and its outcome. The New Indian Journal of OBGYN. 2022; 8(2): 321 - 23. 
removal done on postoperative day 6 and was discharged on postoperative day 7. In NICU prostaglandin infusion was given for 3 days and then stopped in view of poor prognosis after cardiologist opinion. 2D echo was done, report showed as hypoplastic left heart syndrome with aorta and mitral atresia, hypoplastic aorta and transverse arch, severe pulmonary hypertension. Prognosis after surgical correction of the condition is bad and has been explained to the parents but they were not willing for surgery thus baby was discharged on day 8 of life. Baby was brought to hospital on day 21 of life with cold peripheries and gasping breaths. Baby was intubated, chest x-ray showed extensive infiltrates and right sided opacification and was considered as pneumonia. Baby went into cardiac arrest and shock, despite all resuscitative efforts, the baby could not be survived.

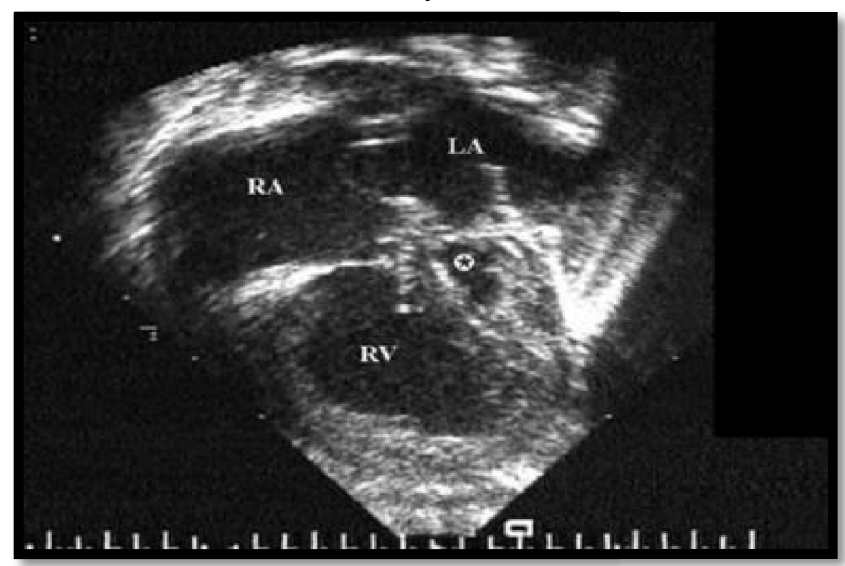

Figure 1: USG showing HLHS

\section{Discussion}

Hypoplastic left heart syndrome may includes underdevelopment of left ventricle, aorta and aortic arch and mitral atresia or stenosis. This syndrome can be diagnosed by anomaly scan and confirmed by fetal echocardiography and further evaluation may include genetic testing. Prenatal diagnosis helps mainly in counseling the parents about the prognosis of the disease and plan for delivery in tertiary centre.

As soon as the baby is delivered, normal physiological changes occurs which leads to lethal hemodynamic disturbances in HLHS neonate ${ }^{8}$. The three major hemodynamic changes occur are gradual decrease in pulmonary vascular resistance, spontaneous constriction of ductus arteriosus and inadequacy of the interatrial connection ${ }^{9}$. Coarctation of the aorta may impede retrograde blood flow to a diminutive ascending aorta and thus decrease the adequacy of coronary blood flow ${ }^{10,11}$. Because of all these changes systemic and coronary blood flow decreases which leads to tissue hypoxia, metabolic acidosis which further leads to vascular shock and death ${ }^{9,10}$.

Most of the babies present with respiratory distress, tachypnea and mild cyanosis, shock and less commonly with severe cyanosis between 1-3 days of life ${ }^{9}$. Survival rate is only 4.5 days as it is associated with $95 \%$ mortality. Most infants die within first two weeks of life ${ }^{9,11,12}$. Some infants will survive beyond 60 days without any surgical intervention but there will be a development of pulmonary hypertension ${ }^{11,13}$.

Medical management is difficult if these babies are to survive. Some medical management has been studied using ACE inhibitors but no benefits are seen ${ }^{14}$. Ideal medical management for this remains inconclusive.

Surgical management includes traditional surgical staged palliation which consists of norwood procedure at birth, a stage II superior cavopulmonary connection, generally performed at 4-6 months of age. Now recently hybrid procedure has been proposed instead of initial norwood procedure as hybrid is less invasive but physiology remains same in both norwood and hybrid procedure. Perioperative survival rate for norwood operation is $47-85 \%$. Recently, there has been renewed enthusiasm for right ventricle to pulmonary artery shunt (RVPAS) as a source of pulmonary blood flow for the norwood procedure. But disadvantage of this is needed to perform a ventriculotomy, with the potential risk to ventricular function and arrhythmia generation. Predictions made that cardiac transplantation would be the final option. Babies who survive with stage 1 palliation may not be suitable for further procedures, for these infants cardiac transplantation may be considered but rejection is the major cause of death after transplantation ${ }^{15}$.

\section{Conclusion}

Once the diagnosis is confirmed, counseling is necessary. Options are optimal therapy i.e from no intervention to surgical therapy. Palliative or comfort care is ideal option for many parents. With palliative therapy long term immunosuppression is possible. Side effect leads to high operative mortality and also affects the quality of life. Cardiac transplantation has got high operative survival but associated with severe rejection. For this type of cases, termination of pregnancy is advisable.

\section{Conflict of interest: None. Disclaimer: Nil.}


The New Indian Journal of OBGYN. 2021 (January-June);8(2)

\section{References}

1. Morris CD, Samanek M, et al. Hypoplastic left heart syndrome: natural history in a geographically defined population. Pediatrics. 1990; 85(6): 977-83.

2. Chameides L, Brownell LG, et al. The Regional Infant Cardiac Program. A six year evaluation. Conn Med. 1975; 39(11): 709-710.

3. Lev M. Pathologic anatomy and interrelationship of hypoplasia of the aortic tract complexes. Lab Invest. 1952; 1: 61-70.

4. Noonan JA, Nadas AS. The hypoplastic left heart syndrome: an analysis of 101 cases. Pediatr Clin North Am. 1958; 5:1029-56.

5. Barber G. Hypoplastic left heart syndrome. In: Garson A, Bricker JT, Fisher DJ, Neish SR, eds. The Science and Practice of Pediatric Cardiology. 2nd edn. Baltimore: Williams and Wilkins.1998.

6. Elzenga NJ, Jonas RA, et al. Coarctation and related aortic arch anomalies in hypoplastic left heart syndrome. J Thorac Cardiovasc Surg. 1985; 8: 379-89.

7. Perloff JK. The hypoplastic left heart. In: Perloff JK, ed. The Clinical Recognition of Congenital Heart Disease, 4th edn. Philadelphia: WB Saunders Co.1994. pp.727-37.

8. Cohen DM, Allen HD. New developments in the treatment of hypoplastic left heart syndrome. Curr Opin Cardiol.1997;12: 44-50.

9. Rosenthal A. Physiology, diagnosis and clinical profile of the hypoplastic left heart syndrome. Progress Ped Cardiol. 1996; 5:19-22.

10. Charpie JR, Kulik TJ. Pre- and post-operative management of infants with hypoplastic left heart syndrome. Progress Ped Cardiol 1996; 5: 49-56.
11. Hoshino K, Ogawa K, Hishitani T, Kitawaza R, Uehara R. Hypoplastic left heart syndrome: Duration of survival without surgical intervention. Am Heart J.1999; 137: 535-42.

12. Jacobs ML, Blackstone EH, Bailey LL. Intermediate survival in neonates with aortic atresia: a multiinstitutional study. J Thorac Cardiovasc Surg. 1998;116: 417-31.

13. Morris CD, Outcalt J, Menashe VD. Hypoplastic left heart syndrome: natural history in a geographically defined population. Pediatrics. 1990; 85: 977-1000.

14. Hsu DT, Zak V, Mahony L, Sleeper LA, Altmann K, Ghanayem NS, Margossian R, Chung WK, et al. Pediatric Heart Network Investigators. Enalapril in infants with single ventricle: results of a multi-center randomized trial. Circulation. 2010;122: 333 - 40.

15. Razzouk AJ, Chinnock RE, Gundry SR, Bailey LL. Cardiac transplantation for infants with hypoplastic left heart syndrome. Progress Ped Cardiol. 1996; 5: 37-47.

\footnotetext{
Akshatha DS ${ }^{1}$, Shakuntala $\mathrm{PN}^{2}$, Sreelatha $\mathrm{S}^{3}$, Sumayya ${ }^{4}$, Shruthi ${ }^{5}$

${ }^{1}$ Junior Resident, Department of Obstetrics and Gynaecology, ESIMC PGIMSR, Rajaji nagar, Bangalore, Karnataka, India; ${ }^{2}$ Assistant Professor, Department of Obstetrics and Gynaecology, ESIMC PGIMSR, Rajaji nagar, Bangalore, Karnataka, India; ${ }^{3}$ Professor, Department of Obstetrics and Gynaecology, ESIMC PGIMSR, Rajaji nagar, Bangalore, Karnataka, India; ${ }^{4}$ Junior Resident, Department of Obstetrics and Gynaecology, ESIMC PGIMSR, Rajaji nagar, Bangalore, Karnataka, India; ${ }^{5}$ Junior Resident, Department of Obstetrics and Gynaecology, ESIMC PGIMSR, Rajaji nagar, Bangalore, Karnataka, India.
} 